\title{
You Could Have Just Asked: The Perception of Motivations to Play Violent Video Games
}

\author{
Julia Kneer $^{1}$, Ruud Jacobs ${ }^{2}$, Christopher J Ferguson ${ }^{3}$ \\ ${ }^{1}$ Erasmus University Rotterdam, The Netherlands \\ ${ }^{2}$ University of Twente, The Netherlands \\ ${ }^{3}$ Stetson University, USA \\ Correspondence: Julia Kneer, Erasmus University Rotterdam, The Netherlands.
}

Received: June 26, 2018

doi:10.11114/smc.v6i2.3389

\author{
Accepted: July 17, 2018 \\ Online Published: July 17, 2018 \\ URL: https://doi.org/10.11114/smc.v6i2.3389
}

\begin{abstract}
Recent research has found that age and playing experience moderates people's opinions regarding video games' negative effects while the perception of the cause of game play - game play motivation - was not considered so far. This study investigated how age and playing expertise influence perceived game play motivations. A survey was performed on a sample of mixed age $(N=374)$. Categories found for perceived playing motivations for violent video games were: virtual aggression, fun/challenge, catharsis, boredom, and social. Fun/challenge was found to be the main motivations for both, non-players and players. However, age positively and playing experience negatively predicted the importance of the perceived motivation virtual aggression while the opposite pattern was found for fun/challenge. The discussion focuses on: 1.) How we should deal with such in- and out-group perceptions in game studies, 2.) how beliefs about player motivations influence further perceptions, and 3.) the necessity of understanding how society's perception of games can influence game science itself.
\end{abstract}

Keywords: game play motivations, playing expertise, age, perception, violent video games

\section{Introduction}

\subsection{Discussion About Violent Video Games and Research Questions}

Research in the field of violent video games is still more than just ambivalent (Elson \& Ferguson, 2013). Some studies found no association between violent video game play and aggressive reactions (e.g., Elson, Breuer, Van Looy, Kneer, \& Quandt, 2014; Ferguson et al., 2008) while others found and still "believe" in negative effects of violent video game playing (Arriaga et al., 2015; Ellithorpe, Cruz, Velez, Ewoldsen, \& Bogert, 2015).

Aside from one recent cordial exchange (Ferguson \& Konijn, 2015), these debates tend to end up in strong positions, with scholars, policy makers, and the general public vehemently arguing very different perspectives. It is unclear why a single pool of research data produces such discrepant opinions about what it means. One possible explanation for the discrepant views is mostly ignored: age differences and therefore generation conflicts. While the older generation is concerned about an increase of anti-social behavior and emotional instability due to violent games with which they are unfamiliar, young players tend to be skeptical of negative effects potentially to defend their identity as gamers (Kneer, Glock, Beskes, \& Bente, 2012; Kneer, Munko, Glock, \& Bente, 2012). Perception on the other hand is also influenced by experience/expertise with a subject (Greenwald \& Banaji, 1995) and guided by pre-existing attitudes and knowledge (Greenwald et al., 2002; Shiffrin \& Schneider, 1977).

Indeed, research has found that the perception of violent games as well as the perception of their effects are strongly influenced by pre-existing experience with games among students (Ivory \& Kalyanaraman, 2009), the general public (Przybylski, 2014), and among scholars (Ferguson \& Colwell, 2015, 2017). The same influence was found for the perception of players in terms of personality characteristics (Kneer, 2010). Most of this prior scholarship has considered opinions regarding the potential impact of games. However, there is still one major part missing in research: the perception of game play motivations (see Figure 1). In other words, do people's opinions about why people play video games differ as a function of age, just as perceptions of effects do?

It remains unclear whether this perception of game play motivations is influenced in the same way as the perception of 
games, players, and game effects. Thus, our study focused on the perception of game play motivations for violent video games and whether perceptions about why people play violent video games differ due to age and playing expertise. We sought to answer the following questions:

RQ1) Can the same categories that were detected for game play motivations be used for the perception of those?

RQ2) To what extent does in-group membership of being a player or not being a player influence the perceived importance of different game play motivations?

RQ3) To what extent can age and personal playing experience predict the perception of game play motivation?

Age \& Playing Expertise



Perception

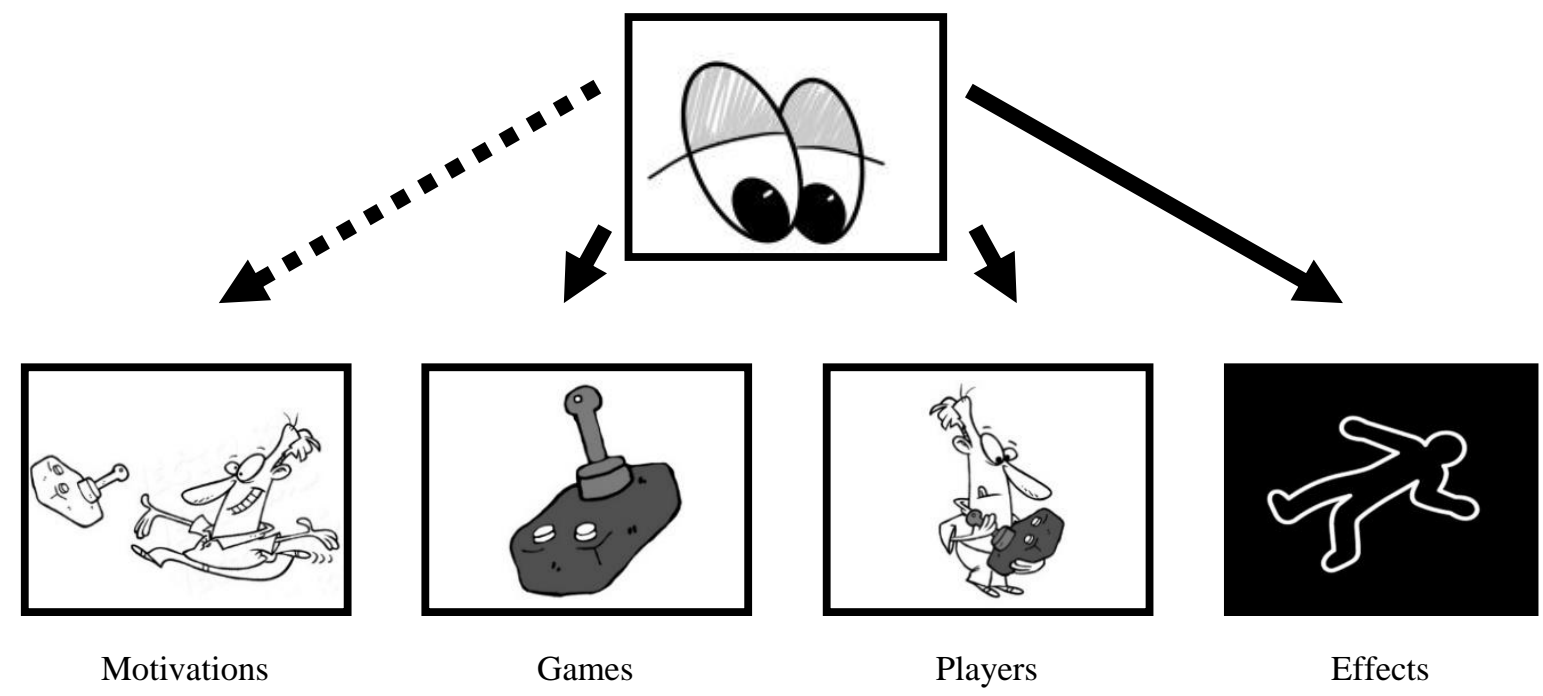

Figure 1. The influence of age and playing expertise on the perception of games, players, and effects which were supported by recent research. If age and playing expertise are also influencing the perception of game play motivations is unclear

\subsection{Perception of Games, Effects, and Players}

With regards to the perception of violent video games and their potential negative influence on children, age and playing expertise seems to be of major influence on people's perceptions of games. Playing expertise as well as age led to defensive reactions in game studies of players - in case players were confronted with the common belief that violent video games are dangerous (Kneer, Munko, et al., 2012). Interestingly enough, not only players but young non-players also defended video games in order to protect a famous activity among their peers. The authors found that aggressive concepts were still activated but suppressed due to implicit defense mechanisms which were activated by the priming of violent game content. Another study proved that this suppression of aggressive concepts was enabled by the increased activation of positive related categories such as social interaction and achievement (Kneer, Glock, et al., 2012). Thus, the expectation of positive outcomes has an appreciable impact on perception of the games. These studies demonstrated that violent games are connected to social interaction and achievement and not to aggression per se. If younger people observe their friends using even violent games for the fulfilment of the needs for relatedness and challenge, not only the motivations themselves to play violent games but their perception should already be linked to social reasons and competition, rather than antisocial motivations. Thus, even young non-players should think that these motivations are the reasons for players to play violent video games, whereas older adults without such exposure may be less familiar with such motivations and presume more antisocial motives. This perception should not only be influenced by playing expertise but moderated by age in case of no existing playing expertise, as age defines the membership of the net generation (Tapscott, 1998). Younger people who belong to the net generation judge games differently than older people even if they do not play themselves - due to their in-group (Kneer, Beskes, \& Bente, 2011).

In addition to the perception of games, past research has offered support for the hypothesis that age and experience 
influence beliefs about negative effects of video games. Ivory and Kalyanaraman (2009) showed that beliefs about negative effects were reduced when an individual considered concrete examples of games they have played themselves. This clearly speaks for the impact of expertise on the perception of game effects. Another study found age to have impact on perception of effects in combination with own playing knowledge. Older people that did not play games hold significantly more negative beliefs towards violence in games (Przybylski, 2014). Two further studies found this to be true also for clinicians who work with children and families (Ferguson, 2015a), as well as scholars (Ferguson \& Colwell, 2017). Interestingly not only age and experience, but hostile attitudes toward youth themselves predicted negative beliefs about violent video games, findings the authors argued support Moral Panic Theory. These findings suggest that not only research on violent video game effects but the perception of such effects is ambivalent and is based again on age and - in case of older age - playing experience.

Other studies which focused on impression formation found that judgments about a player are influenced by a given game genre, and again age of participants, and own playing experience (Kneer, Beskes, et al., 2011). Especially judgments for emotional instability and aggression differed due to own playing behavior (study 1) and younger participants had more positive spontaneous trait inferences in case the perceived person was supposed to regularly play shooter games (study 2). Interestingly enough, based on these results it can be concluded that older persons and/or non-players did not judge a player of violent games as more aggressive and less stable compared to a player of car racing games. Instead, younger persons judged this person as less aggressive and more stable, which clearly points towards a protective behavior as well. In line with the findings from Kneer et al. (2012), Ivory and Kalyanaraman (2009), Pryzbylski (2014), and Ferguson and Collwell $(2107,2015)$ this suggests that playing behavior only plays a role when persons are older. Younger persons seem to have not negative but positive attitudes towards (violent) games and their players even if they do not play themselves at all.

In sum, age and playing expertise was found to have a strong impact on the perception of games, their effects, and the players. Thus, the perception of game play motivations might be influenced as well.

\subsection{Findings on Game Play Motivations of Players}

Self-Determination Theory (SDT; Przybylski, Ryan, \& Rigby, 2009) states that video games provide an opportunity to fulfil particular human needs which sometimes cannot be satisfied in the real world. Moreover, the model suggests that video games may have the ability to meet three critical needs: autonomy, relatedness, and competence (Ferguson \& Olson, 2013; Reinecke et al., 2012; Tamborini, Bowman, Eden, Grizzard, \& Organ, 2010). The autonomy need proposes that players can feel as though they have some form of power or control that they may not be able to experience in the real world. The social relatedness need suggests that video games can deliver opportunities for players to bond socially during the game. Competence needs relate to how video game players feel as if they are able to have important influences on a fictional world, despite not always feeling important in the real world. In addition to these three factors, catharsis and boredom were investigated by Ferguson and Olson (2013) for violent game play motivation. Catharsis is hereby defined as a strategy of escapism from the real world which was already included in the game play motivations for online role games found by Yee (2006). Boredom on the other hand simply stands for having "nothing else to do". Ferguson and Olson (2013) found that the main motivation for players was social interaction/relatedness and that video game play was considered as social event. In line with other studies (Durkin \& Barber, 2002; Klimmt \& Hartmann, 2006) fun and challenge were found to be the basic motivations to play violent video games, which can be thought of as synonymous with challenge. Additionally, the idea that these games can be used to relieve stress (catharsis) turned out to be an important motivation to play these kind of games (Ferguson \& Olson, 2013) and this may have some overlap with autonomy needs.

In sum, research on the active motivations for (violent) video game play revealed five dimensions: autonomy, socialization, competence, catharsis, and boredom. These five dimensions might also appear for the perception of violent game play motivations.

\subsection{Third-Person Perception}

There is a lot of debate regarding whether third-person questions evoke the same responses as first person questions or lead to extreme differences in the answer behaviors, especially if questions are asked about media effects and individual susceptibility to media persuasion. The idea is that some persons think that they are less influenced by (mass) media than other people are (Davison, 1983). This is defined as the so-called Third-Person Effect which is well known and established its own research field (Perloff, 2002). This effect was found for studies in the field of mass communication (e.g., Atwood, 1994), advertisement (e.g., Youn \& Faber, 2000), and persuasion (White \& Dillon, 2000). This has impact on the perception of censorship as people tend to agree with media restriction not in order to protect themselves but to protect others due to the third-person effect (e.g., Rojas, Shah, \& Faber, 1996). However, it is worth noting that the Third-Person Effect deals only with the perception that oneself is immune to media influences while others are not. 
It does not deal effectively with those who are skeptical about effects both for oneself and for others, a different phenomenon increasingly common among young media consumers. Thus, there is a difference between the third-person-effect, and general skepticism.

Nonetheless, it is worth querying if addressing players by asking them third-person questions about their perceptions of game play motivations of others also leads to this effect. So far, some studies have documented the Third-Person Effects for the perception of harmful effects of violent games (Scharrer \& Leone, 2008), although other studies have indicated more general skepticism (Kneer et al., 2012). On the other hand, it was found that the third-person effect was not influenced by priming participants with harmful effects of games (Schmierbach, Xu, \& Boyle, 2012). This difference between having a third-person effect and the lack of influence of similar findings concerning the negative influences of games is simple to explain and lies within the reason for a third-person effect: People who are asked questions about influences of media on themselves and on others immediately start comparing themselves to others. The healthy outcome for the self is a downward comparison, thus, having the impression that one is better, smarter, and of course less influenced than others, resulting in so-called healthy optimism (Gunther \& Mundy, 1993). Thus, answers to third-person questions are less biased and therefore more reliable when it comes to sensitive topics like game play motivations for violent video games (Gunther \& Mundy, 1993). Among younger individuals, for whom gaming is a normal and routine activity for their peers if not themselves, and who are generally skeptical of effects, the third-person effect may not be an issue. However, this is worth investigating.

Asking third-person questions might lead to the assumption that players increase the importance for "negative" playing motives such as "aggression release" and decrease the meaning of "positive" motivations like social reasons due to the third-person effect. Judgements for game play motivations of non-players and experienced players should therefore converge towards a more negative perspective. However, results of studies on the perception of games, game effects, and players speak against this assumption. Expertise in terms of video games still led to neglecting negative effects violent games are supposed to have when judged by non-players (Ivory \& Kalyanaraman, 2009; Przybylski, 2014), and extreme positive responses towards persons who like to play violent games (Kneer, Beskes, et al., 2011). The positive attitude of younger persons and experienced players seems to result in a protection of the peers instead of downward judgments. Therefore, the perception of motivations for violent game play should also be influenced positively by age and playing expertise - even when asked via third-person questions.

\subsection{Hypotheses}

While studies on the topic of perception and video games did focus on games, players, and outcomes, the perception of game play motivations has been ignored so far. This seems like an oversight, as motivations moderate exposure to video games - playing videogames is almost always a self-directed activity. Motivations further direct maintenance of gaming hobbies and enjoyment of specific genres or games. If judgments about players as well as about games and their effects are biased due to playing expertise and age, the perception of gaming motivation as reasonable or anti-social should demonstrate age and experience effects as well.

Before we can test if perception of game play motivations are influenced by age and playing expertise, we need to test if systematic motivation categories can be found. Our first goal was to replicate the dimension structure found by Ferguson and Olson (2013) for violent game play motivations for the third-person view and to test if a further dimension can be established that might be crucial to test for the biased perception of motivations: virtual aggression. We assume that:

H1) The structure for perceived motivations for violent video game play is the same as the dimensions found by Ferguson and Olson (2013).

H2) There will be a further factor for perceived motivations for violent video game play namely 'aggression in virtual environments'.

H3) Being a player has impact on the perception of game play motivations. Non-players judge negative motivations as higher and positive motivations as lower while players show the opposite pattern within their perceptions.

H4) Age has a positive influence on the perception of negative motivations such as virtual aggression and a negative influence on the perception of positive motivation such as fun.

H5) Playing expertise has a negative influence on the perception of negative motivations such as virtual aggression and a positive influence on the perception of positive motivations such as having fun and being social.

\section{Methods}

\subsection{Measurements}

Perceived motivations for violent video game play. To assess perceived motivations, 20 questions were asked via 
5-point Likert scales $(1=$ strongly disagree, $5=$ strongly agree $)$. Sixteen questions were derived from Ferguson and Olson (2013) and slightly altered by using the $3^{\text {rd }}$ person narrative. Four new items were created and added which measured perceived motivation for 'aggression in virtual environments'. Two of the new items targeted mere enjoyment of virtual violence (e.g., "They enjoy the violent content within the games") and while the other two were related to the idea that violent games offer the possibility to act out violent fantasies without causing harm (e.g., "They can live out their own violent fantasies"). All items are displayed in table 1.

Playing expertise: Participants answered six questions regarding own playing behavior/expertise with video games. The first question focused on known players ("how many persons (family and friends) do you know that regularly play video games?"), the second and the third questions focused on own playing behavior in general ("do you regularly play video games?", "how many hours do you spend playing video games per week?"), and the fifth and sixth question were about violent video game play ("do you regularly play violent video games?", "how many hours do you spend playing violent video games per week?”).

\subsection{Procedure}

Participants were recruited by students of an international communication and media study program via several social network sites such as Facebook, LinkedIn, etc. We used a snowball sampling strategy and did not reveal the main goal of the study within the link to the online questionnaire. All participants filled in an anonymous online survey. The survey took approximately five minutes and started with an introduction, including the topic and a consent form. The participant had to confirm his/her participation and understanding of the terms before the actual survey started. First, the 20 motivation-oriented questions were asked followed by the questions regarding playing expertise. At the end, demographic questions were asked and participants were thanked.

\subsection{Sample}

The sample included 374 participants $(56 \%$ female) and $67 \%$ of which were below 40 years old $(M=32.17, S D=$ 14.14). Gender was equally distributed, $\chi^{2}(1)=0.36, n$.s. between older participants ( $>40$ years) and younger ones $(<$ 40 years). The majority of participants had either a Bachelor's (19.52 \%), a Master's (35.29\%), or a high school degree $(40.91 \%)$. Most participants were of Dutch origin $(65.51 \%)$ followed by Czech participants (19.79\%). Of all participants 120 indicated to play video games on a regular basis, 70 of them played violent video games. Mean playing time for the gamers was $M=7.54$ hours/week, $S D=7.47$ and for violent video games (in case they indicated playing them) was $M=5.19$ hours/week, $S D=5.31$. On average, participants indicated to know between 5-6 persons who regularly play violent video games $(M=5.22, S D=10.62)$. For all participants, age was negatively correlated with playing hour/week, $r=-.17, p<.01$, as well as with numbers of violent video game players known, $r=-.14, p<.01$. Number of violent video game players known was positively related to own playing hours per week: $r=.26, p<.01$.

\section{Results}

\subsection{Dimensions of Perceived Motivations for Violent Video Game Play (RQ1, H1, and H2)}

Our first research question was if the same categories for game play motivations of Ferguson and Olson (2013) can be found. We assumed that the structure for perceived motivations for violent video game play is the same as the dimensions found by Ferguson and Olson (2013) (H1) and that there would be a further factor for perceived motivations for violent video game play, 'aggression in virtual environments' (H2). To test for these assumptions, the 20 motivation items were entered into a factor analysis using Principal Components extraction with Promax rotation with five fixed factors to expect. The resultant model explained $54 \%$ of the variance in perceived motivations for violent video game play. Factor loadings of individual items onto the five factors are presented in Table 1. 
Table 1. Factor analysis for perceived game play motivations. Coefficients in the Table represent factor loadings.

\begin{tabular}{|c|c|c|c|c|c|}
\hline & $\begin{array}{r}\text { Virtual } \\
\text { aggression }\end{array}$ & $\begin{array}{r}\text { Fun/ } \\
\text { challenge }\end{array}$ & Catharsis & Social & Boredom \\
\hline Their friends also play these games & - & - & - & .524 & - \\
\hline They like to teach others how to play & - & - & - & .803 & - \\
\hline It helps them to make new friends & - & - & - & .508 & - \\
\hline $\begin{array}{l}\text { They like to mod games (e.g., they change } \\
\text { the game using computer code) }\end{array}$ & - & - & - & .677 & - \\
\hline It is something to do when they are bored & - & - & - & - & .638 \\
\hline There is nothing else for them to do & - & - & - & - & .462 \\
\hline It helps them to relax & - & - & .410 & - & - \\
\hline It helps them to feel less lonely & - & - & .702 & - & - \\
\hline It enables them to create their own world & - & - & .614 & - & - \\
\hline It helps them to release their aggression & - & - & .602 & - & - \\
\hline It helps them to forget their problems & - & - & .592 & - & - \\
\hline They simply find it fun to do & - & .694 & - & - & - \\
\hline It helps them to learn new things & - & - & - & - & - \\
\hline They find the games to be exciting & - & .761 & - & - & - \\
\hline They like to compete with other people & - & .748 & - & - & - \\
\hline $\begin{array}{l}\text { They enjoy the challenge of understanding } \\
\text { the game }\end{array}$ & - & .643 & - & - & - \\
\hline $\begin{array}{l}\text { They enjoy the violent content within the } \\
\text { games (e.g. they like the blood and fighting } \\
\text { scenes) }\end{array}$ & .667 & - & - & - & - \\
\hline They can live out their own violent fantasies & .789 & - & - & - & - \\
\hline $\begin{array}{l}\text { They are able to commit aggressive or } \\
\text { violent acts which they cannot commit in the } \\
\text { real world }\end{array}$ & .799 & - & - & - & - \\
\hline $\begin{array}{l}\text { They enjoy committing violent acts due to } \\
\text { the fact that violence is something that is } \\
\text { frowned upon by society }\end{array}$ & .805 & - & - & - & - \\
\hline
\end{tabular}

Note: Only factor loadings $>.40$ are displayed.

The five factors represent the same four factors found by Ferguson and Olson (2013) and one additional factor (= H1 and H2). Thus, our first and second hypotheses can be accepted, although the boredom scale had very low reliability. Perceived game play motivations do not differ from actual game play motivations. In addition, we can include a further factor: aggression in virtual environments. The factors found were:

Virtual aggression. The first factor identified represents perceived game play motivations due to living out aggression in a virtual environment. It consisted of the extra four items, Cronbach's $\alpha=.80$.

Fun/challenge. The fun/challenge factor consists of the same items found by Ferguson and Olson, Cronbach's $\alpha=.70$ versus .78 observed by Ferguson and Olson (2013, p. 159). Only 'learning new things' did not contribute to this dimension.

Catharsis/escapism. The third factor found represents perceived motivations concerning escape from "the real world" and compensation for problems like frustration and anger, Cronbach's $\alpha=.62$ versus .80 (see Ferguson \& Olson, 2013, p. 159). It includes the same five items as found by Ferguson and Olson (2013).

Social. The fourth factor found represents four perceived game play motivations that are linked to social relatedness such as friendship and contact, Cronbach's $\alpha=.59$ versus .59 (see Ferguson \& Olson, 2013, p. 159).

Boredom. The final factor found consists of only two items which represent perceived motivations which are linked to boredom or having nothing else to do, Cronbach's $\alpha=.38$ versus .62 (see Ferguson \& Olson, 2013, p. 159).

The values for the reliabilities of the four replicated factors were similar to the findings of Ferguson and Olson (2013), with the exception of the boredom factor which had to be excluded due to a low Cronbach's alpha. All other scales were averaged into new variables for further analyses. Thus, these findings mean that our first RQ1 can be answered with yes, the dimensions found are in line with the ones found from Ferguson and Olson (2013).

\subsection{Differences Between Players and Non-Players (RQ2 and H3)}

To analyze if players and non-players judge the reasons to play violent video games differently as questioned within RQ2, a mixed factorial 2 (group: players vs. non-players) x 4 (motivations: virtual aggression, fun/challenge, catharsis, social) ANOVA with repeated measurements on the last factor was conducted (see table 2 for all means and standard 
deviations). Differences between the motivations was the within factor for this analysis. There was no main effect for group $F(1,371)=1.45, p>.23, \eta_{\mathrm{p}}{ }^{2}=.004$ but one was found for motivations, $F(3,369)=146.32, p<.001, \eta_{\mathrm{p}}{ }^{2}=.543$ and a significant interaction effect for group and motivations $F(3,369)=21.28, p<.001, \eta_{\mathrm{p}}{ }^{2}=.147$ (see table 2 for all means and standard deviations).

Table 2. Means and standard deviations of perceived game play motivations for violent video games for players and non-players

\begin{tabular}{llcl}
\hline & & & \\
Motivations & group & $M$ & $S D$ \\
\hline Social & player & 3.05 & 0.65 \\
& non-player & 3.26 & 0.60 \\
Catharsis & player & 3.56 & 0.62 \\
& non-player & 3.50 & 0.64 \\
Fun/challenge & player & 3.98 & 0.56 \\
& non-player & 3.64 & 0.53 \\
Virtual aggression & player & 2.58 & 0.82 \\
& non-player & 2.99 & 0.84 \\
\hline
\end{tabular}

Further $t$-tests for paired samples revealed that players judged fun/challenge the most important motivation compared to virtual aggression, $t(119)=14.85, p<.001$, social, $t(119)=12.75, p<.001$, and catharsis, $t(119)=5.99, p<.001$. The next most important motivation for players was found to be catharsis compared to virtual aggression, $t(119)=12.36, p$ $<.001$ and social, $t(119)=6.83, p<.001$. In addition, social was also judged by players to be of more importance than virtual aggression, $t(119)=5.10, p<.001$.

Interestingly, the results of paired sample $t$-tests for non-players showed the same pattern and not the opposite pattern as expected. Non-players perceived fun/challenge again as the most important motivation compared to virtual aggression, $t(252)=10.65, p<.001$, social, $t(252)=8.11, p<.001$, and catharsis, $t(252)=3.13, p<.01$. Catharsis was also judged as second most central motivation by non-players compared to virtual aggression, $t(252)=4.75, p<.001$ and social, $t(252)=4.85, p<.001$. Social was still judged as more essential than virtual aggression, $t(252)=4.75, p<.001$.

Despite these unforeseen results, comparisons via independent $t$-tests proved as expected that players perceived social, $t(371)=3.10, p<.01$, and fun/challenge motivations, $t(371)=5.67, p<.001$ as more important than non-players did. Virtual aggression was judged more essential motivation by non-players than by players, $t(371)=4.44, p<.001$. The perception of catharsis motivation did not differ, $t(371)=0.85, p>.40$.

Based on these results, we can state that being an in-group member of players does have an effect on the perception of playing motivations (RQ2). However, H3 stated that non-players judge negative motivations as more important than positive motivations. Our analyses showed the opposite pattern of this hypothesis. At the same time, the finding that players and non-players still differed on positive fun/challenge motivations was in line with $\mathrm{H} 3$.

\subsection{Age and Playing Expertise as Predictors for Perceived Motivations for Violent Game Play (RQ3, H4, and H5)}

To investigate if age and personal playing expertise had an impact on the perceived motivations for violent video game play (RQ3), multiple hierarchical regression analyses were conducted. In the first step we included age (H4: Age has a positive influence on the perception of negative motivations such as virtual aggression and a negative influence on the perception of positive motivation such as fun) while personal playing hours and number of colleagues/friends that play violent video games known was entered in the second step (H5: Playing expertise has a negative influence on the perception of negative motivations such as virtual aggression and a positive influence on the perception of positive motivations such as having fun and being social). Results showed that age and own playing expertise were the only significant predictors for two perceived motivations: aggression in virtual environments and fun/challenge. While age was found to positively predict aggression in virtual environments as perceived motivation it was a negative predictor for fun/challenge $(=\mathrm{H} 4)$.

Table 3. Age and personal playing expertise as predictors for virtual aggression in virtual environments as perceived motivation for violent video game play

\begin{tabular}{lll}
\hline & Model 1 & Model 2 \\
Predictor & $.21 * * *$ & $.17^{* *}$ \\
Age & & $-.13^{*}$ \\
Number of hours played per week & & -.08 \\
\hline$R^{2}$ & $.04 * * *$ & $.07 *$ \\
\hline
\end{tabular}

Note: $* p<.05, * p<.01 * * * p<.001$ 
The same pattern was found for own playing behavior in hours per week. Number of known violent video game players predicted the perception of fun/challenge but not virtual aggression as game play motivations $(=$ H5). Please see Table 3 and 4 for standardized coefficients and $R^{2}$. Thus, our fourth and fifth hypotheses can be accepted and we can state that playing expertise and age do have an impact on the perception of playing motivations (RQ3).

Table 4. Age and personal playing expertise as predictors for fun/challenge as perceived motivation for violent video game play

\begin{tabular}{lll}
\hline Predictor & Model 1 & Model 2 \\
\hline Age & $-.27^{* * *}$ & $-.22^{* * *}$ \\
Number of hours played per week & & $.19^{* *}$ \\
Number of known players violent games & $.07^{* * *}$ & $.16^{*}$ \\
\hline$R^{2}$ & $.14^{* * *}$ \\
\hline
\end{tabular}

Note: $* p<.05, * p<.01 * * * p<.001$

\section{Discussion}

Considering that violent games and their potential influences are still under considerable public debate, it may help us to understand factors related to perceptions of violent games and motives for why people play them. Despite decades of research, laboratory, correlational, and longitudinal studies have failed to provide a conclusive answer regarding violent game effects. This lack of clear data has provided fertile ground for diverse opinions among both scholars and the general public on the topic of violent video games.

The opinion about which positive and negative effects occur due to games might not only differ due to being a player or belonging to a different age-group but can also affect how one perceives this seemingly never-ending discussion between generations about video games - especially violent ones (Glock \& Kneer, 2009). So far, we know that playing expertise and age influence such perceptions of games, their players, and their effects. What was missing and thus, was addressed by this study was whether the perception of game play motivations for violent games are also influenced by age and playing expertise.

To analyze these assumptions, we first focused on the structure behind different perceived game play motivations and were able to find similar patterns as Ferguson and Olson did (2013). Additionally, we included items for a further factor: aggression in virtual environments. The data revealed that aggression in virtual environments was indeed an additional dimension next to fun/challenge, social, and catharsis. We also found boredom as further dimension but its reliability was too low to state a successful replication of this game play motivations.

Yet, we can accept our first two hypotheses. Dimensions for perceived motivations asked via third-person questions are the same as dimensions found for first-person questions. This is first evidence that third-person questions are useful for this kind of research, especially because items that address a contentious topic (virtual aggression) can be included and do not lead to reactance or socially desirable answer tendencies which both can distort coherency within a data structure.

The next goal was to investigate if players and non-players differed concerning their perceptions of the importance of different game play motivations for violent games. As assumed, players judged positive motivations such as social and fun/challenge as more important than non-players while the opposite was found for virtual aggression. Non-players tended to assume that attraction to virtual aggression was more important as a motivation for playing violent games than players did. However, both players and non-players demonstrated a similar overall hierarchy of motivations, with fun/challenge judged as the most essential motivation, followed by catharsis and social with virtual aggression at the lower end of the importance scale.

This finding speaks only partly for our third hypotheses, as we expected non-expertise to result in negative judgments about game play motivations. Nevertheless, the finding that the pattern (fun as most important, aggression as least important - independent of game expertise) was further confirmed by analyses concerning the impact of age and playing expertise on the perception of game play motivations. Expertise was only of moderate predictive value for virtual aggression. Playing behavior in hours/week correlated negatively with the perception of virtual aggression as game play motivation but number of players known who like to play such games did not predict virtual aggression as perceived motivation at all. Not surprisingly, the most important predictor found for this model was age. This again speaks for a clear generation difference resulting in different perceptions of games in general - and this time in dissimilarities of perceived game play motivations in specific. However, the variance explained by this analysis was rather small.

Playing hours, number of known players of violent games, and age were all demonstrated as predictors for the perception of fun/challenge of violent games. Interestingly enough, fun/challenge was reported to be the most important motivation for violent games in general (e.g., Sherry, Greenberg, Lucas, \& Lachlan, 2006). The understanding of this 
motivation, and thus, the perception of it must be influenced by existing knowledge about game play motivations. Yet, the comparisons with players and non-players revealed that persons with playing expertise judged it even higher than non-expertise persons, but the importance compared to other motivations was evaluated the same.

Seeing that fun/challenge, catharsis, and social reasons are not only judged as more important than virtual aggression by players but also by non-players and including the finding that virtual aggression is mostly predicted by age one could ask: Will the discussion about the link between violent games and aggression soon be over?

The prediction inherent in this question is based on several observations. 1) Playing expertise will grow in the future and its predictive value for perception on games will diminish. It was found for age and expertise to impact all perceptions of game motivations, games, players, and game effects. Game expertise is growing due to an increasing popularity of games in general (Vorderer, Hartmann, \& Klimmt, 2003). As expertise is growing, everybody will either play themselves or at least will know someone else who does. Other knowledge sources such as media reports or public discussions become of less importance. The variation within knowledge about games and playing expertise will decrease and no longer have predictive value. Put another way: as players age into the power structure of society, society will be more familiar and less concerned with games, even violent ones. This is similar to patterns for prior moral panics on other media such as comic books or rock music (Kneer, Rieger, Frischlich, \& Munko, 2011). 2) In time, there will be no generation left without playing expertise. If expertise is no longer of predictive value because the lack of game knowledge no longer exists, age might be the only influence on perceptions on games. Yet, expertise and age are correlated. Not only are the generations which grew up without video games getting older; its members are introduced to players by having children and grandchildren. Even those who never got in touch with games will soon know some player(s). Thus, age is likely to increasingly lose predictive power for perceptions of games in the next few decades. Or, put another way, fear over video games is caught in time in a particular generation and is thus, restricted in its existence. 3) The positive view on games will increase. Negative links to games, especially violent games, are neglected not only by players but by younger persons as they protect a common hobby of their peers. This defense mechanism is strengthened by the development of expertise, as explained previously. In order to protect/defend video games against all negative accusations, the positive outcomes of games will be stressed (Kneer, Glock, et al., 2012). These positive outcomes are not only assumed but demonstrated by research (Rieger, Frischlich, Wulf, Bente, \& Kneer, 2014). Media effect research concerning the positive side of games, including violent ones, is increasing and will have more impact on the general debate regarding game effects.

Does this mean that we can ignore age and playing expertise such as playing behavior in studies on games? The answer is clearly no, certainly not at present. Despite the development of expertise and the decreasing lack of knowledge about games, reactance behavior and socially desirable behavior in game studies will still occur. As contentious as the topic of game-based violence is, it may be difficult for research studies to get unbiased responses to lab protocols involving games. Unfortunately, some evidence suggests this may extend to researchers themselves, with researcher expectancy effects influencing violent game studies. For instance, studies which employ citation bias (i.e. implying effects are consistent and failing to cite null studies) have been found to correlate with higher effect sizes as opposed to studies that cite evidence on both sides of the debate (Ferguson, 2015b). Thus, we have to check for these effects and offer an environment that helps to reduce negative attitudes towards research on games of all participants in game science: the younger ones, the game experienced ones, the researchers, and the others.

\section{References}

Arriaga, P., Adrião, J., Madeira, F., Cavaleiro, I., Maia e Silva, A., Barahona, I., \& Esteves, F. (2015). A “dry eye" for victims of violence: Effects of playing a violent video game on pupillary dilation to victims and on aggressive behavior. Psychology of Violence, 5(2), 199-208. http://doi.org/10.1037/a0037260

Atwood, L. E. (1994). Illusions of media power: The third-person effect. Journalism \& Mass Communication Quarterly, 7l(2), 269-281. https://doi.org/10.1177/107769909407100202

Davison, W. P. (1983). The third-person effect in communication. Public Opinion Quarterly, 47(1), 1. https://doi.org/10.1086/268763

Durkin, K., \& Barber, B. (2002). Not so doomed: Computer game play and positive adolescent development. Applied Developmental Psychology, 23(4), 373-392. https://doi.org/10.1016/S0193-3973(02)00124-7

Ellithorpe, M. E., Cruz, C., Velez, J. A., Ewoldsen, D. R., \& Bogert, A. K. (2015). Moral license in video games: When being right can mean doing wrong. Cyberpsychology, Behavior, And Social Networking, 18(4), 203-207. https://doi.org/10.1089/cyber.2014.0599

Elson, M., Breuer, J., Van Looy, J., Kneer, J., \& Quandt, T. (2014). Comparing apples and oranges? Evidence for pace of action as a confound in research on violence in digital games. Psychology in Popular Media and Culture. https://doi.org/10.1037/ppm000001 
Elson, M., \& Ferguson, C. (2013). Twenty-five years of research on violence in digital games and aggression: Empirical evidence, perspectives, and a debate gone astray. European Psychologist. https://doi.org/10.1027/1016-9040/a000147

Ferguson, C. J. (2015a). Clinicians' attitudes toward video games vary as a function of age, gender and negative beliefs about youth: A sociology of media research approach. Computers in Human Behavior, online fir.

Ferguson, C. J. (2015b). Do angry birds make for angry children? A meta-analysis of video game Influences on children's and adolescents' aggression, mental health, prosocial behavior and academic performance. Perspectives on Psychological Science., online fir.

Ferguson, C. J., \& Colwell, J. (2015). Scholarly consensus on video game violence effects continues to elude: Examining factors related to differing opinions among scholars on whether violent video games cause societal violence. Paper Presented at the European Congres of Psychology. Milan, Italy.

Ferguson, C. J., \& Colwell, J. (2017). Understanding why scholars hold different views on the influences of video games on public health. Journal of Communication, 1-23. https://doi.org/10.1111/jcom.12293

Ferguson, C. J., \& Konijn, E. A. (2015). She said/he said: A peaceful debate on video game violence. Psychology of Popular Media Culture, online first. https://doi.org/10.1037/ppm0000064

Ferguson, C. J., \& Olson, C. K. (2013). Friends, fun, frustration and fantasy: Child motivations for video game play. Motivation and Emotion, 37(1), 154-164. https://doi.org/10.1007/s11031-0129284-7

Ferguson, C. J., Rueda, S. M., Cruz, A. M., Ferguson, D. E., Fritz, S., \& Smith, S. M. (2008). Violent video games and aggression: Causal relationship or byproduct of family violence and intrinsic violence motivation? Criminal Justice and Behavior, 35(3), 311-332. http://doi.org/10.1177/0093854807311719

Glock, S., \& Kneer, J. (2009). Game Over? The impact of knowledge about violent digital games on the activation of aggression-related concepts. Journal of Media Psychology: Theories, Methods, and Applications, 21(4), 151-160. https://doi.org/10.1027/1864-1105.21.4.151

Greenwald, A. G., \& Banaji, M. R. (1995). Implicit social cognition: Attitudes, self-esteem, and stereotypes. Psychological Review, 102(1), 4-27. https://doi.org/10.1037/0033-295X.102.1.4

Greenwald, A. G., Banaji, M. R., Rudman, L. A., Farnham, S. D., Nosek, B. A., \& Mellott, D. S. (2002). A unified theory of implicit attitudes, stereotypes, self-esteem, and self-concept. Psychological Review, 109(1), 3-25. https://doi.org/10.1037/0033-295X.109.1.3

Gunther, A. C., \& Mundy, P. (1993). Biased optimism and the third-person effect. Journalism \& Mass Communication Quarterly, 70(1), 58-67. https://doi.org/10.1177/107769909307000107

Ivory, J. D., \& Kalyanaraman, S. (2009). Video games make people violent - well, maybe not that game: Effects of content and person abstraction on perceptions of violent video games' effects and support of censorship. Communication Reports, 22(1), 1-12. https://doi.org/10.1080/08934210902798536

Klimmt, C., \& Hartmann, T. (2006). Effectance, self-efficacy, and the motivation to play video games. Playing Video Games - Motives, Responses, Consequences, 133-146.

Kneer, J. (2010). Unreal Tournament?! Der Einfluss von Spielerfahrung auf Vorurteile gegenüber First-Person Shooter Spielern [Unreal Tournament?! The impact of playing experience on prejudice against First Person Shooter players]. In W. Kaminski \& M. Lorber (Eds.), Computerspiele: Medien und mehr... (pp. 85-96). München: Kopaed.

Kneer, J., Beskes, S., \& Bente, G. (2011). Belonging to "Generation Game": Defence atrategies of young adults concerning effects of digital video games. In 12th European Congress of Psychology. Istanbul.

Kneer, J., Glock, S., Beskes, S., \& Bente, G. (2012). Are digital games perceived as fun or danger? Supporting and suppressing different game-related concepts. Cyberpsychology, Behavior, and Social Networking, 15(11), 604-609. https://doi.org/10.1089/cyber.2012.0171

Kneer, J., Munko, D., Glock, S., \& Bente, G. (2012). Defending the Doomed: Implicit strategies concerning protection of First-Person Shooter games. Cyberpsychology, Behavior and Social Networking, 15(5), 251-256. https://doi.org/10.1089/cyber.2011.0583

Kneer, J., Rieger, D., Frischlich, L., \& Munko, D. (2011). Goethe versus Rammstein: who is allowed to play with madness? The influence of musical taste on prejudice against heavy metal lyrics. In C. A. McKinnon, N. Scott, \& K. Sollee (Eds.), Can I play with madness? Metal, Dissonance, Madness \& Alienation. (pp. 3-14). 
Inter-Disciplinary Press.

Perloff, R. M. (2002). The third-person effect. In J. Bryang \& D. Zillmann (Eds.), Media Effects: Advances in Theory and Research (pp. 81-94). https://doi.org/10.1093/ijpor/8.2.120

Przybylski, A. (2014). Who believes electronic games cause real world aggression? Cyberpsychology, Behavior, and Social Networking, 17(4), 228-234. https://doi.org/10.1089/cyber.2013.0245

Przybylski, A., Ryan, R. M., \& Rigby, C. S. (2009). The motivating role of violence in video games. Personality and Social Psychology Bulletin, 35(2), 243-259. https://doi.org/10.1177/0146167208327216

Reinecke, L., Tamborini, R., Grizzard, M., Lewis, R., Eden, A., \& David Bowman, N. (2012). Characterizing mood management as need eatisfaction: The effects of intrinsic needs on selective exposure and mood repair. Journal of Communication, 62(3), 437-453. https://doi.org/10.1111/j.1460-2466.2012.01649.x

Rieger, D., Frischlich, L., Wulf, T., Bente, G., \& Kneer, J. (2014). Eating Ghosts: The underlying mechanisms of mood repair via interactive and noninteractive media. Psychology of Popular Media Culture, online fir. https://doi.org/10.1037/ppm0000018

Rojas, H., Shah, D. V, \& Faber, R. J. (1996). For the good of the others: Censorship and the third-person effect. International Journal of Public Opinion Research, 8(2), 163-186. https://doi.org/10.1093/ijpor/8.2.163

Scharrer, E., \& Leone, R. (2008). First-person shooters and the third-person effect. Human Communication Research, 34(2), 210-233. https://doi.org/10.1111/j.1468-2958.2008.00319.x

Schmierbach, M., Xu, Q., \& Boyle, M. (2012). The Role of exemplification in shaping third-person perceptions and support for restrictions on video games. Mass Communication and Society, 15(5), 672-694. https://doi.org/10.1080/15205436.2011.616278

Sherry, J. L., Greenberg, B. S., Lucas, K., \& Lachlan, K. A. (2006). Video game uses and gratifications as predictors of use and game preference. In P. Vorderer \& J. Bryant (Eds.), Playing Video Games: Motives, Responses, and Consequences (pp. 213-224).

Shiffrin, R. M., \& Schneider, W. (1977). Controlled and automatic human information processing: I. Detection, search, and attention. Psychological Review, 84, 127-190.

Tamborini, R., Bowman, N. D., Eden, A., Grizzard, M., \& Organ, A. (2010). Defining media enjoyment as the satisfaction of intrinsic needs. Journal of Communication, 60(4), 758-777.

https://doi.org/10.1111/j.1460-2466.2010.01513.x

Tapscott, D. (1998). Growing up digital: the rise of the Net generation. New York: McGraw-Hill.

Vorderer, P., Hartmann, T., \& Klimmt, C. (2003). Explaining the enjoyment of playing video games: The role of competition. In D. Marinelli (Ed.), Communication Research (pp. 1-9). Carnegie Mellon University.

White, H. A., \& Dillon, J. F. (2000). Knowledge about others' reaction to a public service announcement: The impact on self persuasion and third-person perception. Journalism \& Mass Communication Quarterly, 77(4), 788-803. https://doi.org/10.1177/107769900007700405

Yee, N. (2006). Motivations for play in online games. Cyberpsychology \& Behavior: The Impact of the Internet, Multimedia and Virtual Reality on Behavior and Society, 9(6), 772-775. https://doi.org/10.1089/cpb.2006.9.772

Youn, S., \& Faber, R. J. (2000). Advertising and the third-person effect. Psychology \& Marketing, 17(7), 633-649. https://doi.org/10.1002/(SICI)1520-6793(200007)17:7

\section{Copyrights}

Copyright for this article is retained by the author(s), with first publication rights granted to the journal.

This is an open-access article distributed under the terms and conditions of the Creative Commons Attribution license which permits unrestricted use, distribution, and reproduction in any medium, provided the original work is properly cited. 